\title{
1-P-064 Poster Sessions
}

\section{Matrix Gla protein negatively regulates calcification of human aortic valve interstitial cells isolated from calcified aortic valves}

\author{
Seya Kazuhiko' ${ }^{1}$ Zaiqiang $\mathrm{Yu}^{2}$, Mari Chiyoya², Wei Yang², Kazuyuki Daitoku², \\ Shigeru Motomura ${ }^{3}$, Tadaatsu Imaizumi ${ }^{1}$, Ikuo Fukuda ${ }^{2}$, Ken-Ichi Furukawa ${ }^{3}$
}

${ }^{I}$ Dept. Vascul. Biol., Hirosaki Univ. Grad. Sch. Med., ${ }^{2}$ Dept. Thorac. Cardiovasc. Surg., Hirosaki Univ. Grad. Sch. Med., ${ }^{3}$ Dept. Pharmacol., Hirosaki Univ. Grad. Sch. Med.

Aortic valve stenosis (AS) is a common heart valve disease in elderly people, and is mostly accompanied by ectopic valve calcification. We recently demonstrated that tumor necrosis factor- $\alpha$ (TNF- $\alpha$ ) induces calcification of human aortic valve interstitial cells (HAVICs) obtained from AS patients. In this study, we investigated the role of matrix Gla protein (MGP), a known calcification inhibitor that antagonizes bone morphogenetic protein 2 (BMP2) in TNF- $\alpha$ induced calcification of HAVICs. HAVICs isolated from aortic valves were cultured, and calcification was induced with $30 \mathrm{ng} / \mathrm{mL}$ TNF- $\alpha$. Gene expression of the calcigenic marker, BMP2, was significantly increased in response to TNF- $\alpha$, while the gene and protein expression of MGP was strongly decreased. To confirm the role of MGP, MGPknockdown HAVICs and HAVICs overexpressing MGP were generated. In HAVICs, in which MGP expression was inhibited by small interfering RNA, calcification and BMP2 gene expression were induced following long-term culture for 32 days. In contrast, HAVICs overexpressing MGP had significantly decreased TNF- $\alpha$-induced calcification. These results suggest that MGP acts as a negative regulator of HAVIC calcification. 